\title{
Surface-Enhanced Raman Scattering Probing the Translocation of DNA and Amino Acid through Plasmonic Nanopores
}

Jin-Mei Yang, ${ }^{\dagger}$ Lei Jin, ${ }^{\star}$ Zhong-Qin Pan, ${ }^{\dagger}, \S$ Yue Zhou, ${ }^{\dagger}$ Hai-Ling Liu, ${ }^{\dagger}$ Li-Na Ji ${ }^{*}, /$ Xing-Hua Xia, ${ }^{\dagger}$ and Kang Wang*, $\uparrow$

$\nmid$ State Key Laboratory of Analytical Chemistry for Life Science, School of Chemistry and Chemical Engineering, Nanjing University, Nanjing 210023, China.

* College of Pharmaceutical Sciences, Zhejiang University, Hangzhou 310058, China.

$\S$ School of Public Health, Institute of Analytical Chemistry for Life Science, Nantong University, Nantong 226019, China.

/ State Key Laboratory of Pharmaceutical Biotechnology, School of Life Sciences, Nanjing University, Nanjing 210023, China.

*E-mail: wangkang@nju.edu.cn, jilina@nju.edu.cn

Table of Content:

1. Characterization of the glass nanopipette.

2. Characterization of the gold seeds.

3. The morphology of the gold plasmonic nanopores (GPNs).

4. The analytical enhancement factor calculation.

5. Specific vibrational assignments of nucleobases and amino acids.

6. Normal Raman spectra of pure nucleobases powders.

7. Various SERS spectra of thymine.

8. Blank experiments.

9. SERS spectra of adenine with different concentrations.

10. SERS-based sulfur-containing amino acid L-Cysteine detection.

11. Identification of single nucleobase in other DNA oligomers. 
1. Characterization of the glass nanopipette.

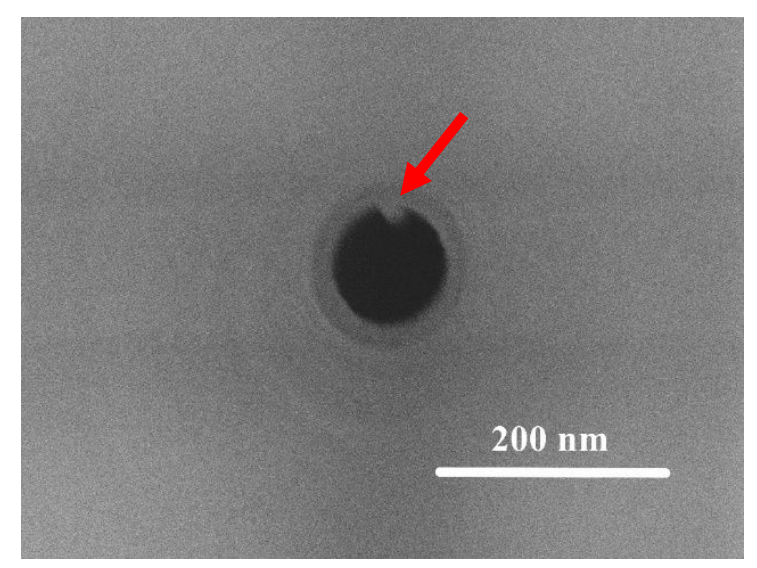

Figure S1. SEM image of the orifice of the glass naonpipette. 
2. Characterization of the gold seeds.
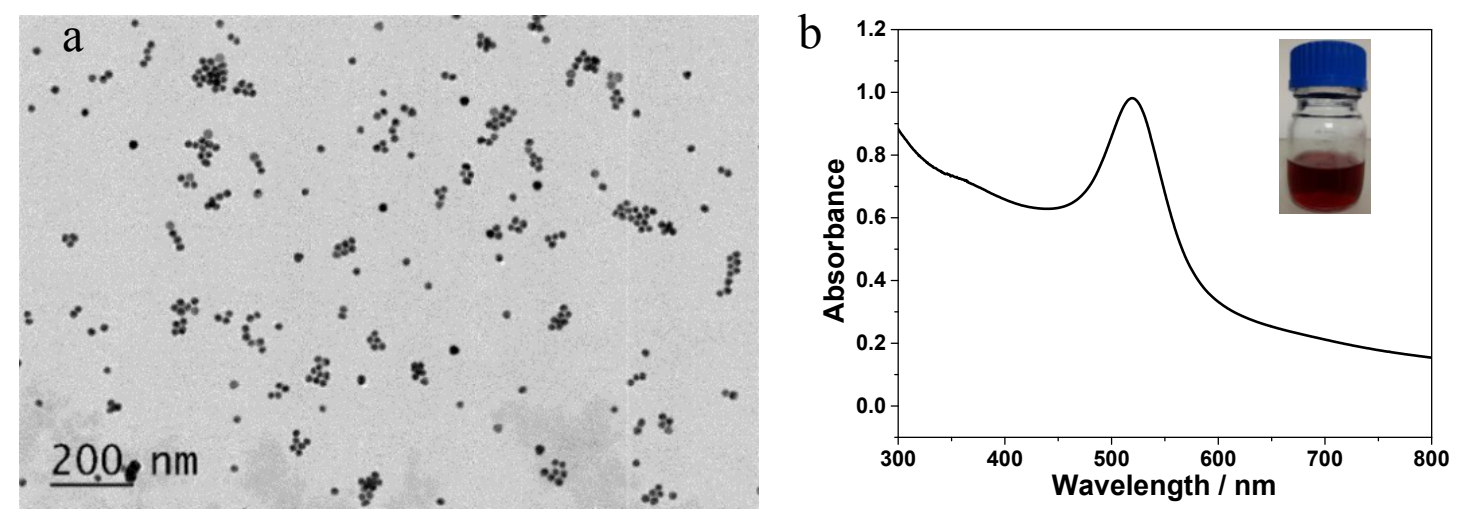

Figure S2. TEM (a) and UV-vis spectra (b) of $15 \mathrm{~nm}$ gold seeds. 


\section{The morphology of the gold plasmonic nanopores (GPNs).}
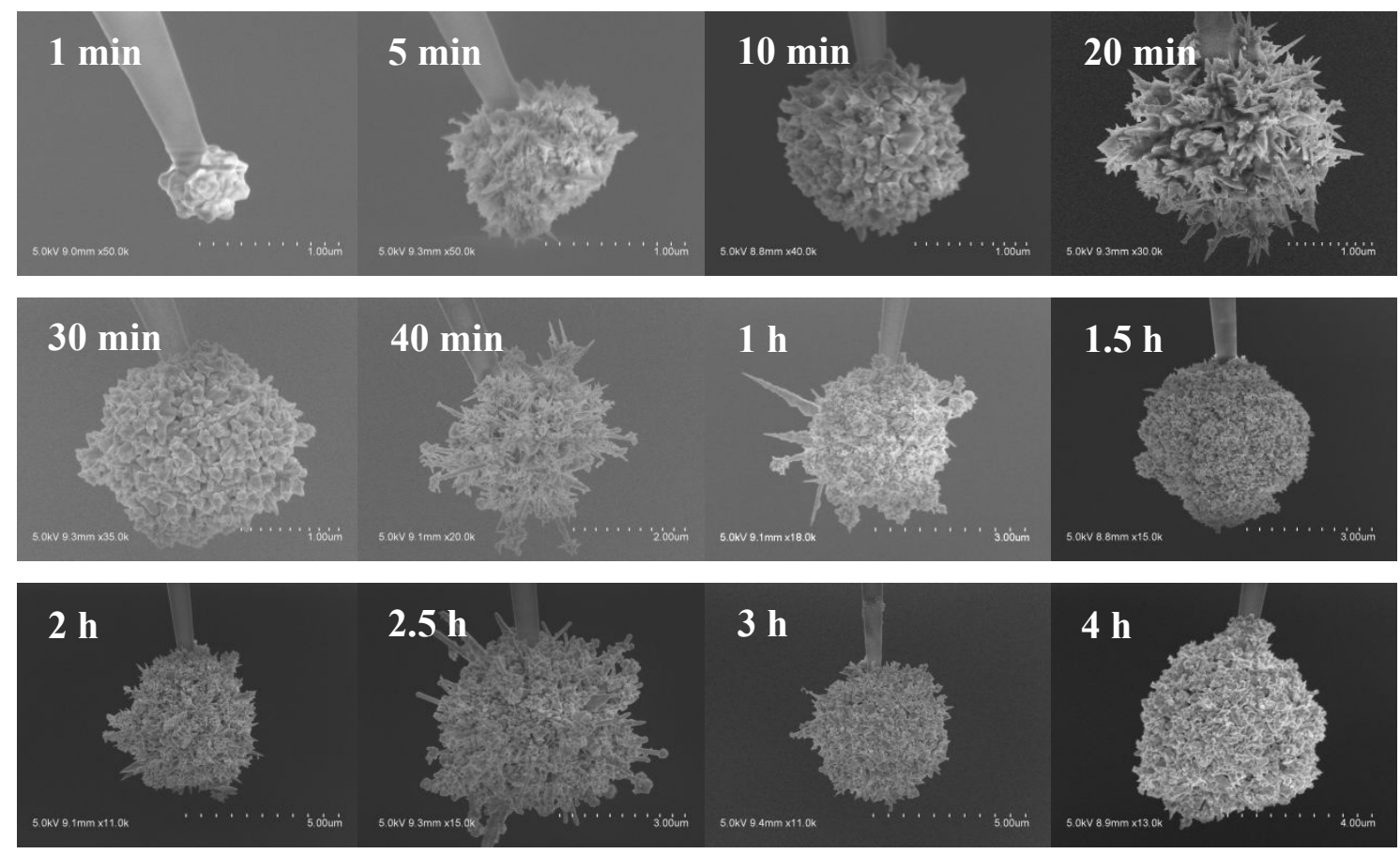

Figure S3. The morphologies of the GPNs with the increase of growth time. The glass nanpipette orifice is $100 \mathrm{~nm}$, and the concentration of ascorbic acid (AA) is $100 \mathrm{mM} .1 \%(\mathrm{~V} / \mathrm{V})$ stoste solution of gold seeds is added in $0.25 \mathrm{mM} \mathrm{HAuCl}_{4}$. The $\mathrm{pH}(6.5)$ of the solution is not adjusted by $\mathrm{HCl}$ or $\mathrm{NaOH}$ and no $\mathrm{NaCl}$ is added in the solution.

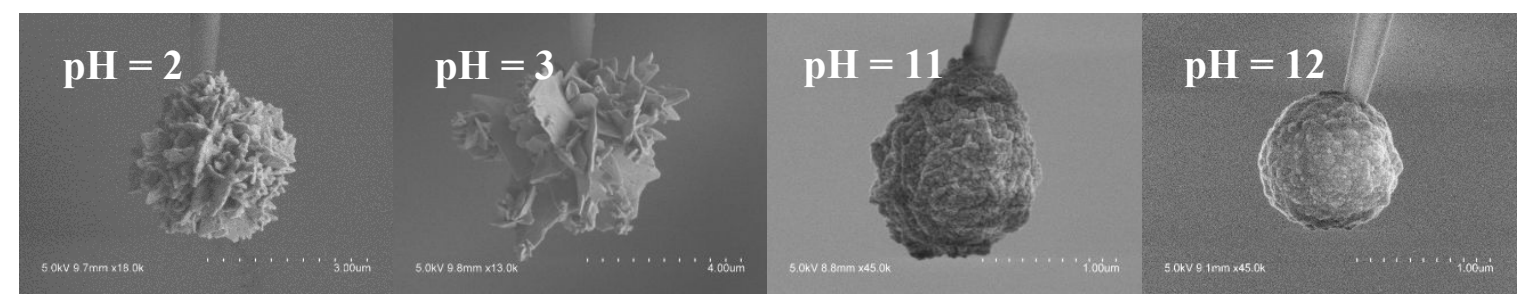

Figure S4. The morphologies of the GPNs fabricated under different $\mathrm{pH}$. The $\mathrm{pH}$ of the $\mathrm{HAuCl}_{4}$ solution is adjusted by adding $1 \mathrm{M} \mathrm{HCl}$ or $1 \mathrm{M} \mathrm{NaOH}$. The reaction time is $3 \mathrm{~h}$. The other parameters are the same as those in Figure S3.

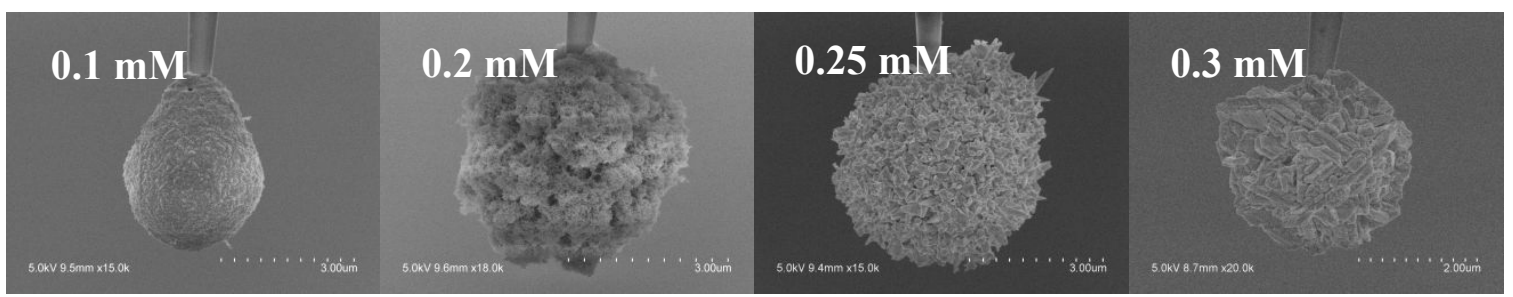

Figure S5. The morphologies of the GPNs fabricated with different concentrations of $\mathrm{HAuCl}_{4}$. The reaction time is $3 \mathrm{~h}$. The other parameters are the same as those in Figure S3. 


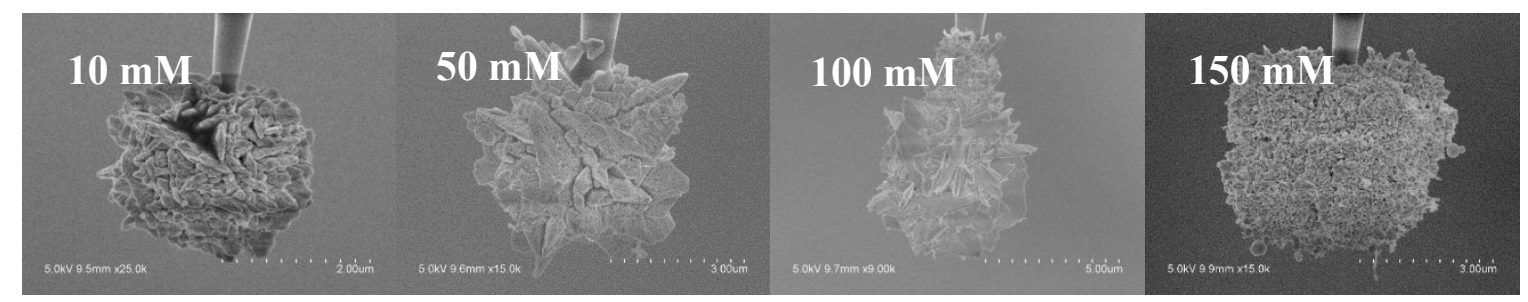

Figure S6. The morphologies of the GPNs fabricated with different concentrations of AA. The reaction time is $3 \mathrm{~h}$. The other parameters are the same as those in Figure S3.

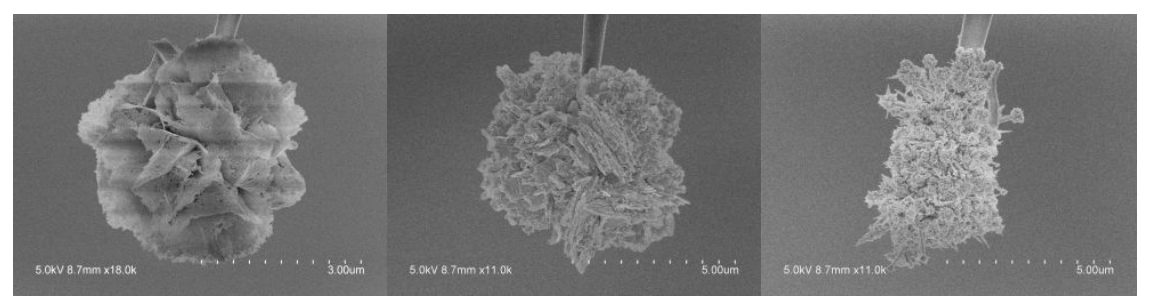

Figure S7. The morphologies of the GPNs fabricated in the absence of the gold seeds. The reaction time is $3 \mathrm{~h}$. The other parameters are the same as those in Figure S3.

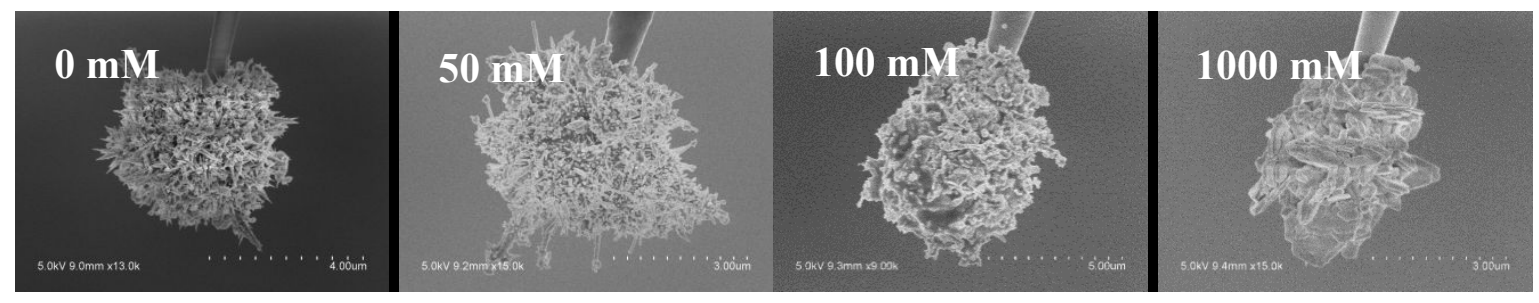

Figure S8. The morphologies of the GPNs fabricated under different $\mathrm{NaCl}$ concentrations in the AA solution. The reaction time is $3 \mathrm{~h}$. The other parameters are the same as those in Figure $\mathrm{S} 3$.

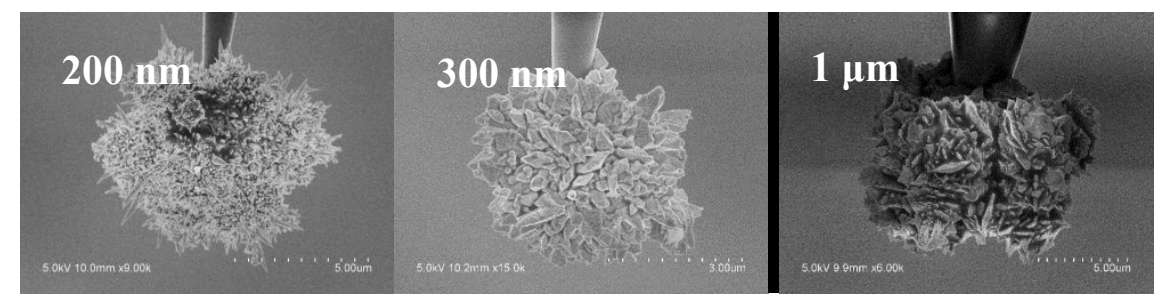

Figure S9. The morphologies of the GPNs fabricated with different nanopipette orifice. The reaction time is $3 \mathrm{~h}$. The other parameters are the same as those in Figure S3.

In the glass nanopipette-confined reduction reaction, the formation, adsorption and grow of GPNs is greatly affected by the properties of reagents, solution and glass/solution interface. Therefore, we systematically studied the following factors to understand their effect on the morphology of GPNs, including the growth time, $\mathrm{pH}$, the concentration of $\mathrm{HAuCl}_{4}$ and $\mathrm{AA}$, presence of gold seeds, salt concentration and the diameter of nanopipette orifice. ${ }^{1,2}$ The SEM 
images of GPNs fabricated under different conditions are presented in Figure S3-S9. Several general rules are obtained: (1) with the increases of growing time, the morphology of GPNs undergoes repeatedly tremendous changes from dense globose to branched shape (Figure S3). (2) Lamellar GPNs structure appears in the acidic solution (adjusted by $\mathrm{HCl}$ ), and the lamellar structure becomes smaller with the decrease of $\mathrm{pH}$. On the contrary, GPNs composed of small nanoparticles are formed in basic solution (adjusted by $\mathrm{NaOH}$ ), and such morphology keep almost constant in basic solutions (Figure S4). (3) With the concentration of $\mathrm{HAuCl}_{4}$ increasing from 0.1 to $0.25 \mathrm{mM}$, the morphology of GPNs changed from small nanoparticles to interlaced sharp corners. The further increase in the $\mathrm{HAuCl}_{4}$ concentration results in the formation of stack-block structure (Figure S5). (4) The morphology of GPNs changes from with sharp corners to with irregular stack-block structure when the AA concentration increases from 10 to $150 \mathrm{mM}$ (Figure S6). (5) Compared with GPNs fabricated in $\mathrm{HAuCl}_{4}$ in the presence of gold seeds (Figure S3), uncontrollable structures are prone to form and the speed of forming GPNs is usually slow in the absence of gold seeds (Figure S7). (6) With the addition of salt $(\mathrm{NaCl})$, the surface charge on glass nanopipette will be screened, then GPNs can attach to the glass tip easily. However, the sharp corners also disappear compared with GPNs formed in the absence of salt (Figure S8). (7) The diameter of glass orifice does not show a great influence on the morphologies of GPNs. As shown in Figure S9, the GPNs morphology shows no big difference when the orifice increases from 100 to $1000 \mathrm{~nm}$, showing that the GPNs morphologies fabricated under the same chemical conditions are relatively constant though the size of glass nanopipettes may vary slightly.

The optimized conditions for GPNs fabrication then was chosen as: glass nanpipette orifice (100 nm), AA (100 mM, without $\mathrm{NaCl}$ solution), pH 6.5 (without addition of $\mathrm{HCl}$ or $\mathrm{NaOH}$ ), with addition of 1:100 (V/V) stoste solution of gold seeds in $\mathrm{HAuCl}_{4}(0.25 \mathrm{mM})$ and react for $3 \mathrm{~h}$. 


\section{The analytical enhancement factor calculation.}

In Figure 1f, the $I_{S E R S}$ at $1360 \mathrm{~cm}^{-1}$ is 14944 , the $I_{\text {Raman }}$ is $4100 . C_{\text {Raman }}$ and $C_{S E R S}$ used in the measurement are $0.025 \mathrm{M}$ and $10^{-7} \mathrm{M}$, respectively. According to equation 1 in the maintext. The AEF is calculated to be $0.9 \times 10^{6}$. The AEFs of different GPNs varies from $5 \times 10^{5}$ to $7 \times 10^{6}$. 
5. Specific vibrational assignments of nucleobases and amino acids

Table S1. Specific vibrational assignments of nucleobases ${ }^{3}$

\begin{tabular}{lcc}
\hline nucleotide & 651 & assignments \\
\hline Raman shift $/ \mathrm{cm}^{-1}$ & 723 & C5-C6 bend, N1-C6 bend breath \\
\hline ring breath \\
ring breath \\
ring def
\end{tabular}

R6, six-membered ring; bend, bending; breath, breathing; def, deformation; str, stretching. 
Table S2. Specific vibrational assignments of amino acids ${ }^{4}$

\begin{tabular}{|c|c|c|c|}
\hline amino acid & structural formula & Raman shift $/ \mathrm{cm}^{-1}$ & assignments \\
\hline \multirow{3}{*}{ Trp } & & 613 & $\mathrm{COO}^{-}$sciss \\
\hline & & 982 & ring breath \\
\hline & & 1101 & $\mathrm{NH}_{2}$ twist \\
\hline \multirow{3}{*}{ Tyr } & & 637 & ring def \\
\hline & & 823 & ring o.p.breath \\
\hline & & 1343 & ring breath, $\mathrm{COO}^{-} \mathrm{str}$ \\
\hline \multirow{4}{*}{ His } & & 665 & $\mathrm{COO}^{-}$rock \\
\hline & & 710 & $\mathrm{COO}^{-}$def \\
\hline & & 818 & ring i.p.breath \\
\hline & & 1222 & ring i.p.def \\
\hline \multirow{3}{*}{ Phe } & & 998 & ring i.p.breath \\
\hline & & 1032 & ring i.p.breath \\
\hline & & 1162 & C-N str \\
\hline \multirow{3}{*}{ Cys } & & 648 & C-S str \\
\hline & & 1079 & C-C str, C-O str \\
\hline & NH & 1358 & C-N str \\
\hline \multirow{3}{*}{ Glu } & & 734 & C-C def \\
\hline & & 1075 & C-N str, C-C str \\
\hline & & 1325 & $\mathrm{CH}_{2}$ twist \\
\hline \multirow{5}{*}{ Gly } & & 606 & $\mathrm{COO}^{-}$wag \\
\hline & & 749 & $\mathrm{COO}^{-}$bend \\
\hline & $\mathrm{COOH}$ & 959 & $\mathrm{CH}_{2}$ rock \\
\hline & & 1229 & $\mathrm{CH}_{2}$ def \\
\hline & & 1473 & $\mathrm{CH}_{2}$ sciss \\
\hline \multirow{4}{*}{ Lys } & & 778 & $\mathrm{COO}^{-}$sciss \\
\hline & соон & 914 & C-C str \\
\hline & & 1164 & {$\left[\mathrm{NH}_{3}\right]^{+}$rock } \\
\hline & & 1197 & $\mathrm{CH}_{2}$ twist \\
\hline
\end{tabular}

Bend, bending; breath, breathing; def, deformation; rock, rocking; sciss, scissoring; str, stretching; wag, wagging; twist, twisting; i.p., in-plane; o.p., out-of-plane. 
6. Normal Raman spectra of pure nucleobases powders.

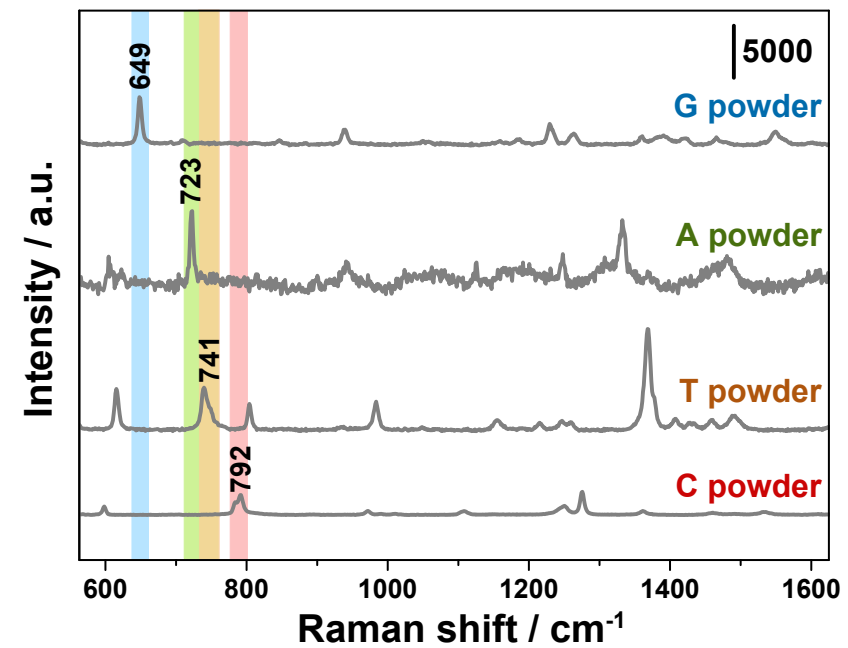

Figure S10. The normal Raman spectra of pure nucleobases powder. Laser line, $633 \mathrm{~nm}$; laser power, $0.85 \mathrm{~mW}$; integration time, $5 \mathrm{~s}$ for 5 times. 


\section{Various SERS spectra of thymine.}

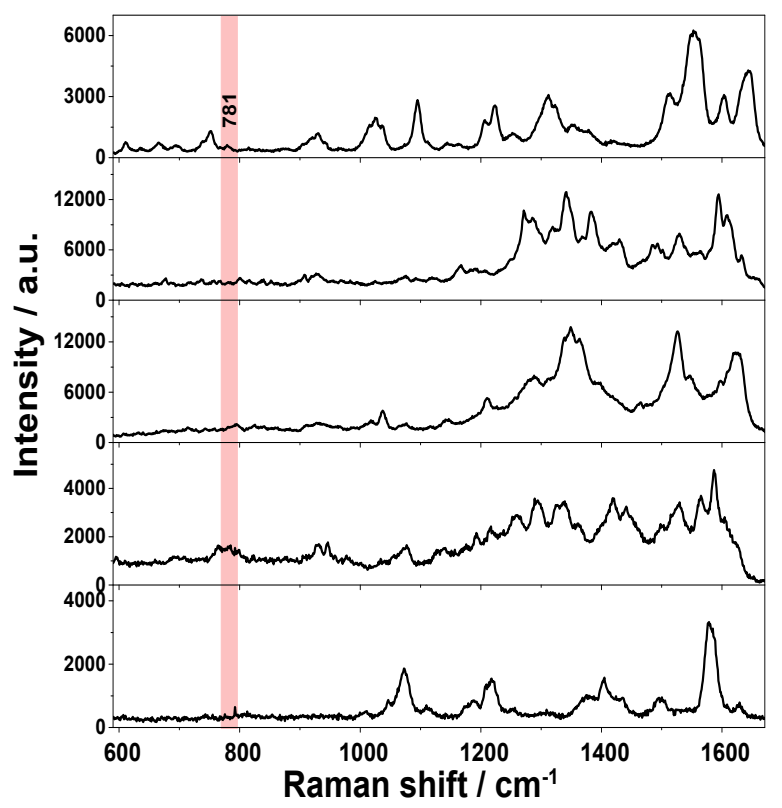

Figure S11. The different SERS spectra of $T$ translocating through GPNs at a bias potential of -1 $\mathrm{V}$. The concentration of T, $10^{-4} \mathrm{M}$; laser line, $633 \mathrm{~nm}$; laser power, $0.85 \mathrm{~mW}$; integration time, $5 \mathrm{~s}$ for 5 times.

Compared with the other three nucleobases, previous work shows the adsorption capacity of thymine $(\mathrm{T})$ on the gold substrate is weaker. ${ }^{5,6}$ Meanwhile there are several types of different SERS spectra due to the presence of two carbonyl and two N-H groups in $\mathrm{T}$ that are possible to bind the substrates. ${ }^{7}$ As expected, such phenomena are also observed in this experiment, which demonstrate the $\mathrm{T}$ base may interact with $\mathrm{Au}$ atoms differently when translocating through the GPNs. 


\section{Blank experiments.}
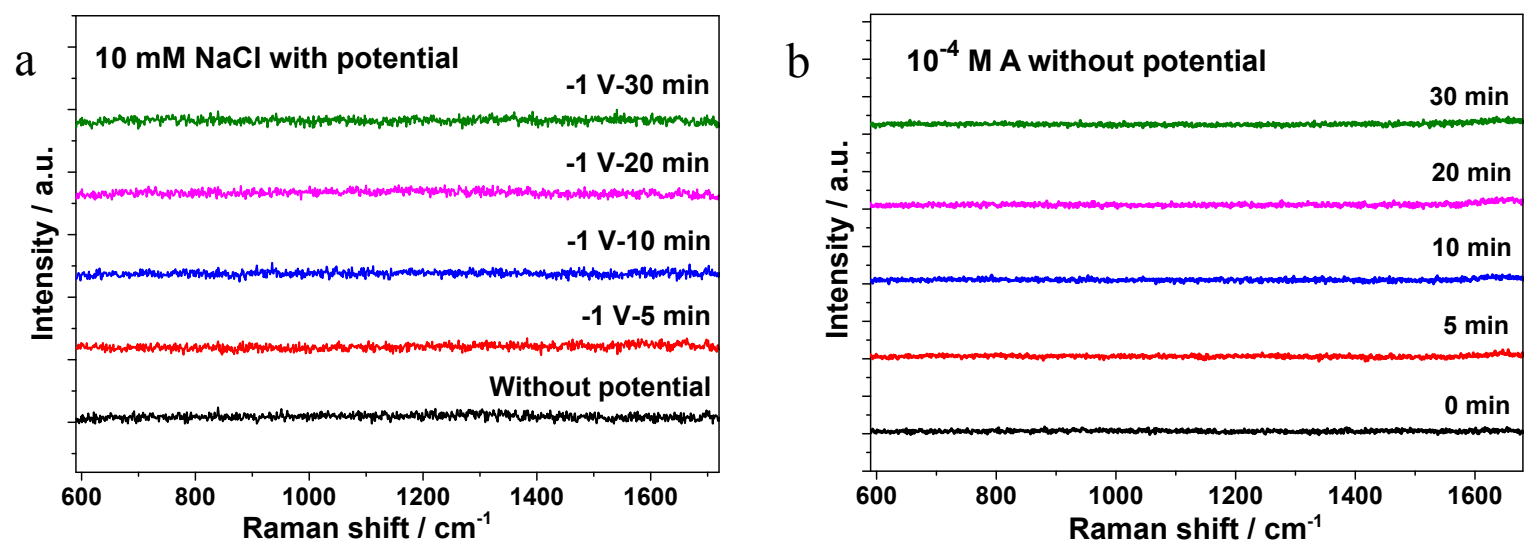

Figure S12. (a) The SERS spectra of $\mathrm{NaCl}(10 \mathrm{mM})$ translocating through GPNs applying bias potential of $-1 \mathrm{~V}$ for different time. (b) The SERS spectra of adenine $\left(\mathrm{A}, 10^{-4} \mathrm{M}\right)$ translocating through GPNs without bias potential for different time. Laser line, $633 \mathrm{~nm}$; laser power, $0.85 \mathrm{~mW}$; integration time, $5 \mathrm{~s}$ for 5 times. 
9. SERS spectra of adenine with different concentrations.

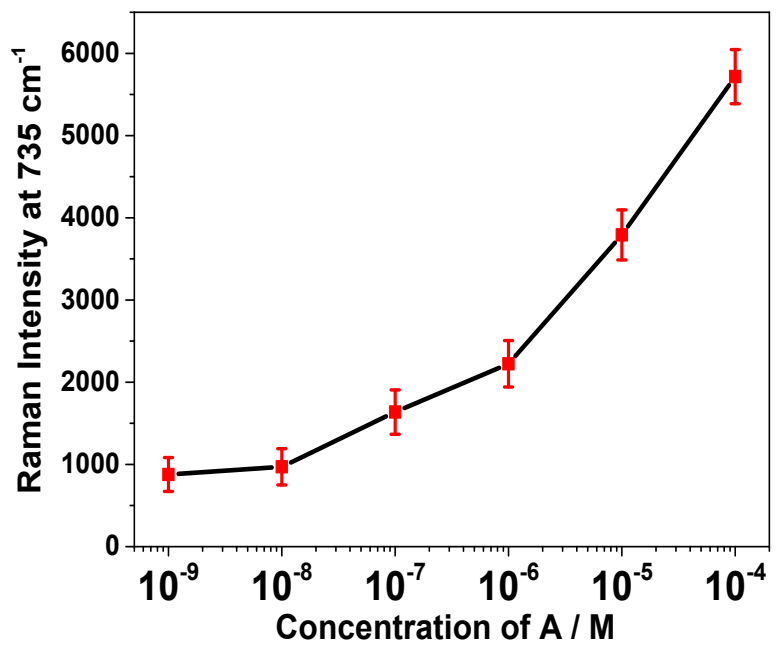

Figure S13. The dependence of SERS intensities at $735 \mathrm{~cm}^{-1}$ on the A concentration. From low to high: $10^{-9}, 10^{-8}, 10^{-7}, 10^{-6}, 10^{-5}$, and $10^{-4} \mathrm{M}$, respectively. Laser line, $633 \mathrm{~nm}$; laser power, 0.85 $\mathrm{mW}$; integration time, $5 \mathrm{~s}$ for 5 times. 


\section{SERS-based sulfur-containing amino acid L-Cysteine detection.}

a

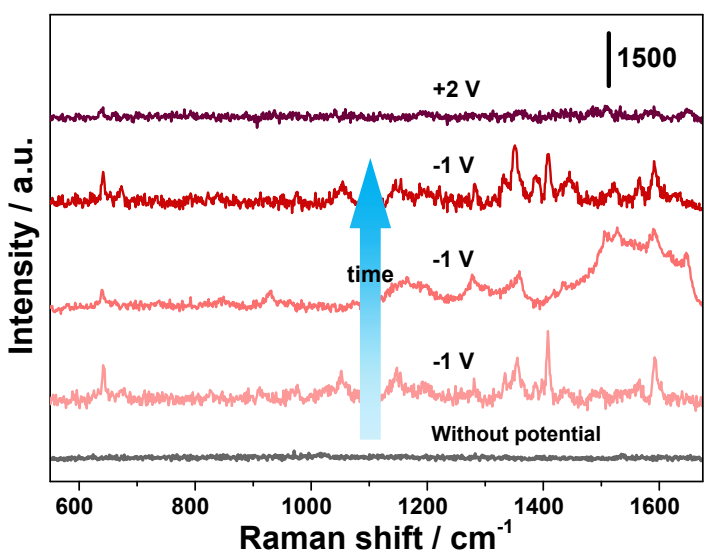

b

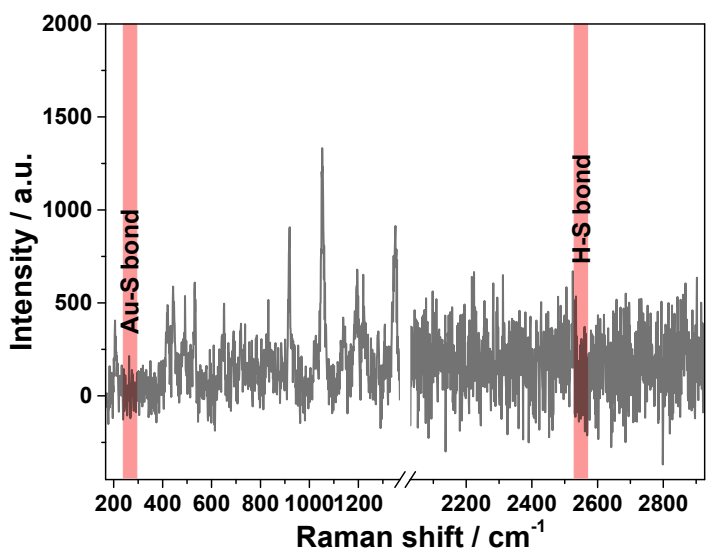

Figure S14. (a) The SERS spectra of L-Cysteine (Cys) at different bias potentials. (b) The SERS spectrum of Cys at a bias potential of $-1 \mathrm{~V}$. The Au-S bond at $264 \mathrm{~cm}^{-1}$ and $\mathrm{H}-\mathrm{S}$ bond at $2558 \mathrm{~cm}^{-1}$ are not observed in our experiment. The laser line, $633 \mathrm{~nm}$; laser power, $0.85 \mathrm{~mW}$; integration time, $5 \mathrm{~s}$ for 5 times.

In our work, the translocation nanopore behavior of sulfur-containing Cys is investigated. When a negative potential of $-1 \mathrm{~V}$ is applied, the characteristic Raman signal of the C-S stretching mode at $\sim 642 \mathrm{~cm}^{-1}$ fluctuates with time (Figure S14). However, the Raman signal drops instantaneously with a bias positive of $+2 \mathrm{~V}$, which indicates that Cys can translocate through the GPNs. The Au-S bond at $264 \mathrm{~cm}^{-1}$ is not observed, indicating the Au-S bond hardly forms in the nanofluid. Therefore, the successful detection suggests that GPNs are promising for use in the translocation property of mass under free state. 


\section{Identification of single nucleobase in other DNA oligomers.}
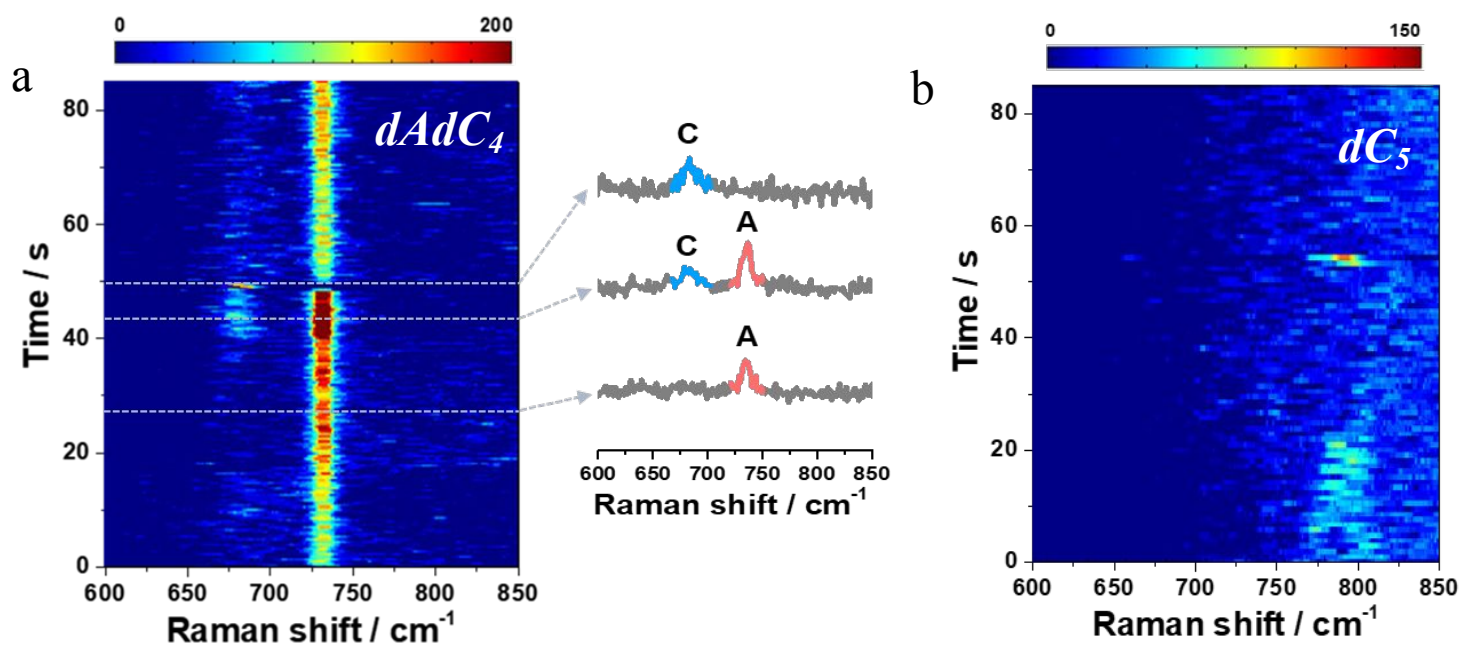

Figure S15. (a) Time-resolved SERS spectral trajectories of ss-DNA oligomer $d A d C_{4}$ through the GPNs at a bias potential of $-1 \mathrm{~V} . d A d C_{4}$ concentration, $10^{-5} \mathrm{M}$. Each spectrum is acquired in $0.1 \mathrm{~s}$. The illustrations represent the temporal traces of the Raman intensity of nucleobases marked in a. (b) Time-resolved SERS spectral trajectories of ss-DNA oligomer $d C_{5}$ through the GPNs at a bias potential of $-1 \mathrm{~V} . d C_{5}$ concentration, $10^{-5} \mathrm{M}$; electrolyte solution, $10 \mathrm{mM} \mathrm{NaCl}$; laser line, $633 \mathrm{~nm}$; the laser power, $17 \mathrm{~mW}$. Each spectrum is acquired in $0.5 \mathrm{~s}$.

To further demonstrate the ability of GPNs distinguishing single nucleobase, the time-resolved SERS spectral trajectories of DNA oligomers (5'-ACCCC-3' and 5'-CCCCC-3', which is denoted as ' $d A d C_{4}$ ' and ' $d C_{5}$ ', respectively) are also measured (Figure S15). As shown in Figure S15a, the SERS signal of $\mathrm{A}$ in $d A d C_{4}$ fluctuates with time. The SERS signal of $\mathrm{C}$ randomly shows up with the ring deformation mode of $\mathrm{C}$ at $\sim 685 \mathrm{~cm}^{-1}$ much stronger than the ring breathing mode at $\sim 795$ $\mathrm{cm}^{-1}$. The relative frequency of showing Raman bands of $\mathrm{C}$ in $d A d C_{4}$ is much lower than that in $d C d A_{4}$ (Figure 3a). This may be caused by the low affinity between $\mathrm{C}$ on gold surface. ${ }^{8}$ That is, the SERS spectrum of $\mathrm{C}$ strongly depends on the number of A in the DNA sequence, which may bring $\mathrm{C}$ closer to the gold surface. Therefore, though the concentration of $\mathrm{C}$ in $d A d C_{4}$ is much higher, $\mathrm{C}$ in $d C d A_{4}$ has more chance to access the hot spots in GPNs than that in $d A d C_{4}$ during translocating through the nanopores. We tried many GPNs in our experiment and all of the C SERS signals are lower than A. $d C_{5}$ shows almost no obvious SERS signal (Figure S15b, peak only shows at $\sim 795 \mathrm{~cm}^{-1}$ ). The selective DNA chain is very short (5 nucleobases), which confirms that the SERS signal can be tuned by modulating by the affinity between the analytes and the plasmonic nanopores. Such phenomenon is also observed by other researchers ${ }^{9}$, where the authors used a poly $(d C) 28 d G d A$ and the SERS intensity of A is still comparable with C. 


\section{References}

(1) Park, Y. I.; Im, H.; Weissleder, R.; Lee, H. Nanostar Clustering Improves the Sensitivity of Plasmonic Assays. Bioconjugate Chem. 2015, 26, 1470-1474.

(2) Yuan, H.; Khoury, C. G.; Hwang, H.; Wilson, C. M.; Grant, G. A.; Vo-Dinh, T. Gold Nanostars: Surfactant-Free Synthesis, 3D Modelling, and Two-Photon Photoluminescence Imaging. Nanotechnology 2012, 23, 075102-9.

(3) Otto, C.; van den Tweel, T. J. J.; de Mul F. F. M.; Greve J. Surf ace-Enhanced Raman Spectroscopy of DNA Bases. J. Raman Spectrosc. 1986, 17, 289-298.

(4) Pazderka, T.; Kopecky Jr, V. Drop Coating Deposition Raman Spectroscopy of Proteinogenic Amino Acids Compared with Their Solution and Crystalline State. Spectrochim. Acta. A 2017, 185, 207-216.

(5) Kimura-Suda, H.; Petrovykh, D. Y.; Tarlov, M. J.; Whitman, L. J. Base-Dependent Competitive Adsorption of Single-Stranded DNA on Gold. J. Am. Chem. Soc. 2003, 125, 90149015.

(6) Demers, L. M.; Östblom, M.; Zhang, H.; Jang, N.-H.; Liedberg, B.; Mirkin, C. A. Thermal Desorption Behavior and Binding Properties of DNA Bases and Nucleosides on Gold. J. Am. Chem. Soc. 2002, 124, 11248-11249.

(7) Aroca, R.; Bujalski, R. Surface Enhanced Vibrational Spectra of Thymine. Vib. Spectrosc. 1999, 19, 11-21.

(8) Piana, S.; Bilic, A. The Nature of the Adsorption of Nucleobases on the Gold [111] Surface. J. Phys. Chem. B 2006, 110, 23467-23471.

(9) Chen, C.; Li, Y.; Kerman, S.; Neutens, P.; Willems, K.; Cornelissen, S.; Lagae, L.; Stakenborg, T.; Van Dorpe, P. High Spatial Resolution Nanoslit SERS for Single-Molecule Nucleobase Sensing. Nat. Commun. 2018, 9, 1733-9. 